\title{
Fabrication and Mechanical Properties of Porous Anisotropic Silicon Nitride with Lutetia Additive
}

\author{
Naoki KONDO, Yoshiaki INAGAKI, ${ }^{* \dagger}$ Yoshikazu SUZUKI ${ }^{\dagger \dagger}$ and Tatsuki OHJII \\ Synergy Materials Research Center, National Institute of Advanced Industrial Science and Technology (AIST), \\ 2268-1, Shimo-Shidami, Moriyama-ku, Nagoya-shi 463-8687 \\ *Synergy Ceramics Laboratory, Fine Ceramics Research Association (FCRA), 2268-1, Shimo-Shidami, Moriyama-ku, Nagoya-shi $463-8687$
}

\author{
ルテチアを焼結助剤とする配向組織窒化ケイ素の作製と機械特性 \\ 近藤直樹·稲垣良昭 $*, \uparrow \cdot$ 鈴木義和 ${ }^{\dagger \dagger} \cdot$ 大司達樹 \\ 産業技術総合研究所シナジーマテリアル研究センター, 463-8687 名古屋市守山区下志段味 2268-1 \\ *ファインセラミックス技術研究組合シナジーセラミックス研究所，463-8687 名古屋市守山区下志段味 2268-1
}

\begin{abstract}
Porous anisotropic silicon nitrides exhibiting superior mechanical properties at elevated temperatures were successfully fabricated. The silicon nitrides containing lutetia $\left(\mathrm{Lu}_{2} \mathrm{O}_{3}\right)$ as sintering additive were fabricated using a partial sinter-forging technique in which uniaxial pressure was applied after heating up to the sinter-forging temperature. Rod-like silicon nitride grains were formed during the heating, and they were aligned by the subsequent forging. Strength of a specimen with porosity of about $23 \%$ was more than $600 \mathrm{MPa}$ at room temperature (R.T.), which was achieved by choosing a suitable sinter-forging condition. It maintained more than $450 \mathrm{MPa}$ even at $1500^{\circ} \mathrm{C}$. Fracture energies at $R . T$. and $1500^{\circ} \mathrm{C}$ were 110 and $150 \mathrm{~J} \cdot \mathrm{m}^{-2}$, respectively. The concurrent achievement of high strength and fracture energy is very likely the result of the combined effects of grain alignment, presence of pores between grains, and the lutetia sintering additive. High strength at elevated temperatures is caused by the lutetia sintering additive. [Received December 19,2003;Accepted April 27,2004]
\end{abstract}

Key-words : Silicon nitride, Porous microstructure, Anisotropic microstructure, High temperature mechanical properties, Strength, Fracture energy

\section{Introduction}

Recently, high-strength porous silicon nitrides have been developed by controlling their porous microstructures. ${ }^{1)-9)}$ One important development for porous silicon nitride $\left(\mathrm{Si}_{3} \mathrm{~N}_{4}\right)$ is the formation of an anisotropic microstructure in which rod-like silicon nitride grains display a high degree of directionality. ${ }^{1,4), 6)-9)}$ Such a microstructure formation engenders excellent mechanical properties when a tensile stress is applied in the alignment direction.

Two major routes can be used to fabricate such porous anisotropic silicon nitrides: a tape casting technique with seed crystals, ${ }^{1), 4), 8)}$ and a partial sinter-forging technique. ${ }^{6)-9)}$ Partial sinter forging is a very simple technique. Rod-like silicon nitride grains that are formed during heating are aligned by subsequent sinter forging with a mechanical press.

Some of the authors reported the fabrication and mechanical properties of the partially sinter-forged silicon nitrides with 5 mass\% yttria $\left(\mathrm{Y}_{2} \mathrm{O}_{3}\right)$ as a sintering additive. ${ }^{6), 7), 9)}$ By choosing suitable fabrication conditions, a relatively high strength of $780 \mathrm{MPa}$ was achieved in the specimen with porosity of about $24 \%$ at room temperature (R.T.). ${ }^{7)}$ Another specimen, whose porosity was also $24 \%$, showed a high fracture energy of $266 \mathrm{~J} \cdot \mathrm{m}^{-2}$ at R.T. ${ }^{7)}$ Strength and fracture energy depended on their grain size. The specimen with smaller grains showed higher strength and lower fracture energy. On the contrary,

\footnotetext{
${ }^{\dagger}$ Present address: Ishikawajima-Harima Heavy Industries Co., Ltd., Shin-Nakahara-cho, Isogo-ku, Yokohama-shi 235-8501 現在：石川島播磨重工業(株), 235-8501 横浜市磯子区新中原町

${ }^{\dagger+}$ Present address: Institute of Advanced Energy, Kyoto University, Gokasyo, Uji-shi, Kyoto 611-0011

現在 : 京都大学エネルギー理工学研究所, 611-0011 京都府宇治 市五ケ庄
}

the specimen with larger grains showed higher fracture energy and lower strength. Those specimens maintained their good mechanical properties up to $1400^{\circ} \mathrm{C}$ because yttria is an advantageous additive for high temperature use. ${ }^{9)}$ Additionally, elastic moduli of the specimens were substantially lowered to 150-180 GPa by introducing pores. ${ }^{7)}$ Relatively high strength and lowered elastic modulus result in higher fracture strain, as indicated by dividing the strength by the elastic modulus.

As mentioned, porous anisotropic silicon nitrides with yttria additive exhibited several superior properties. However, their strength largely degrades above $1400^{\circ} \mathrm{C} .{ }^{9)}$ Presently, the best additive for high temperature use is believed to be lutetia $\left(\mathrm{Lu}_{2} \mathrm{O}_{3}\right) .{ }^{10)-12)}$ Porous anisotropic silicon nitrides with lutetia additive are expected to show better high temperature mechanical properties than those with yttria additive. Thus, in this study, porous anisotropic silicon nitrides with lutetia additive were fabricated by using a partial sinter-forging technique and their mechanical properties were evaluated.

\section{Experimental}

$\alpha$-silicon nitride powder (E10; Ube Industries, Ltd., Tokyo) was used as the starting powder. It was mixed with 10 mass \% $\mathrm{Lu}_{2} \mathrm{O}_{3}$ (Shin-Etsu Chemical Co., Ltd., Tokyo) as the sintering additive, and was ball-milled for $50 \mathrm{~h}$ in methanol using nylon balls. The powder was dried, sieved, and compacted with a uniaxial pressure of $2.5 \mathrm{MPa}$ in a graphite die with a base of $45 \times 45 \mathrm{~mm}$. Partial sinter-forging was conducted using a hot-press furnace. The atmosphere inside the furnace, nitrogen gas (99.99\%) under 0.9 MPa pressure, was maintained throughout the process. The die was heated up to $1900^{\circ} \mathrm{C}$ at a rate of $10^{\circ} \mathrm{C} \cdot \mathrm{min}^{-1}$. After reaching the desired temperature, partial sinter-forging was conducted with a uniaxial mechanical force of $58800 \mathrm{~N}$ (approximately 30 
$\mathrm{MPa})$. Piston transfer was controlled so that the porosity of the sintered specimen became $25 \%$; the forging time was varied from 60 to $180 \mathrm{~min}$. Then, the die was cooled at a rate of $10^{\circ} \mathrm{C} \mathrm{m^{-1 }}$ to $<1000^{\circ} \mathrm{C}$.

Porosity of the fabricated specimen was calculated by dividing the sample mass by the volume. X-ray diffraction analysis was conducted to identify the specimen phases and to examine the orientation of silicon nitride grains. Specimens of $3 \times 4 \times$ $45 \mathrm{~mm}$ for measuring bending strength were cut from the partially sinter-forged body. The stress face was made perpendicular to the pressing direction. Three-point bending strength was measured with a span of $30 \mathrm{~mm}$ and a displacement rate of $0.5 \mathrm{~mm} \mathrm{~min}^{-1}$ at R.T. and elevated temperatures. Fracture energy was measured by a chevron-notched beam (CNB) method. The CNB specimen geometry employed and testing procedures matched those of the previous study. ${ }^{13)}$ The CNB specimen had dimensions of $3 \times 4 \times 45 \mathrm{~mm}$ with a regular triangle shaped ligament (edge length was $3 \mathrm{~mm}$ ). Initial crack length was $1.4 \mathrm{~mm}$; the chevron-notch width was $0.1 \mathrm{~mm}$. Measurements were performed in three-point bending with a span of $30 \mathrm{~mm}$ and a displacement rate of $0.01 \mathrm{~mm} \mathrm{~min}^{-1}$. All measurements at elevated temperatures were done in a nitrogen atmosphere. Fracture surfaces of CNB specimens were observed by scanning electron microscopy (SEM).

\section{Results and discussion}

In this work, three types of specimens with different partial sinter-forging time were fabricated. They were designated as PSN060, PSN090 and PSN180, respectively, because of their forging times of 60,90 and $180 \mathrm{~min}$.

Porosities of PSN060, PSN090 and PSN180 were 26, 23 and $23 \%$, respectively. Those values were close to the expected porosity of $25 \%$. Figure 1 shows fractured surfaces of the fabricated specimens taken from the CNB specimens tested at R.T. The planes parallel to the forging direction were observed in the micrographs. Hereafter, planes normal and parallel to the forging direction were designated as the top $(T)$ and side $(S)$ planes, respectively. All specimens consisted mainly of rod-like silicon nitride grains. The micrographs show that grains were aligned somewhat perpendicularly to the forging direction: anisotropic microstructure formation. The grains were coarser at longer sinter-forging times. Grains of more than $20 \mu \mathrm{m}$ in the length were often found in PSN180.

Figure 2 shows $\mathrm{X}$-ray diffraction analysis results. The patterns were taken from the $T$ and $S$ planes. Detected peaks were from $\beta-\mathrm{Si}_{3} \mathrm{~N}_{4}$ (JCPDS Card 33-1160), $\mathrm{Lu}_{2} \mathrm{SiO}_{5}$ (410239), and $\mathrm{Lu}_{4} \mathrm{Si}_{2} \mathrm{O}_{7} \mathrm{~N}_{2}$ (33-0847), whose formations were expected from a phase diagram. ${ }^{14)}$ Diffraction analysis revealed grain alignment (anisotropy) clearly. The patterns from $T$ and $S$ planes of the fabricated specimens differed considerably. One typical value indicating anisotropy is the peak intensity ratio of $(101) /(210) .{ }^{15)}$ These two peaks stand close together and have strong intensities. In isotropic silicon nitrides, (101) and (210) peaks usually have approximately equal heights; the ratio of $(101) /(210)$ is 1.06 (JCPDS Card 33-1160). On the contrary, Fig. 2 shows that (210) peaks were remarkably higher in the $T$ planes, and lower in the $S$ planes, than (101) peaks. These results indicate that the prismatic plane of the silicon nitride grains tended to be aligned perpendicularly to the pressing direction in fabricated specimens. The ratios were 0.18, 0.21 and 0.20 for PSN160, PSN090 and PSN180, respectively.

Figures 3 and 4 show measured strengths and fracture energies, respectively, together with a previous porous anisotropic silicon nitride with an yttria additive (PSN-Y).$^{9)}$ All
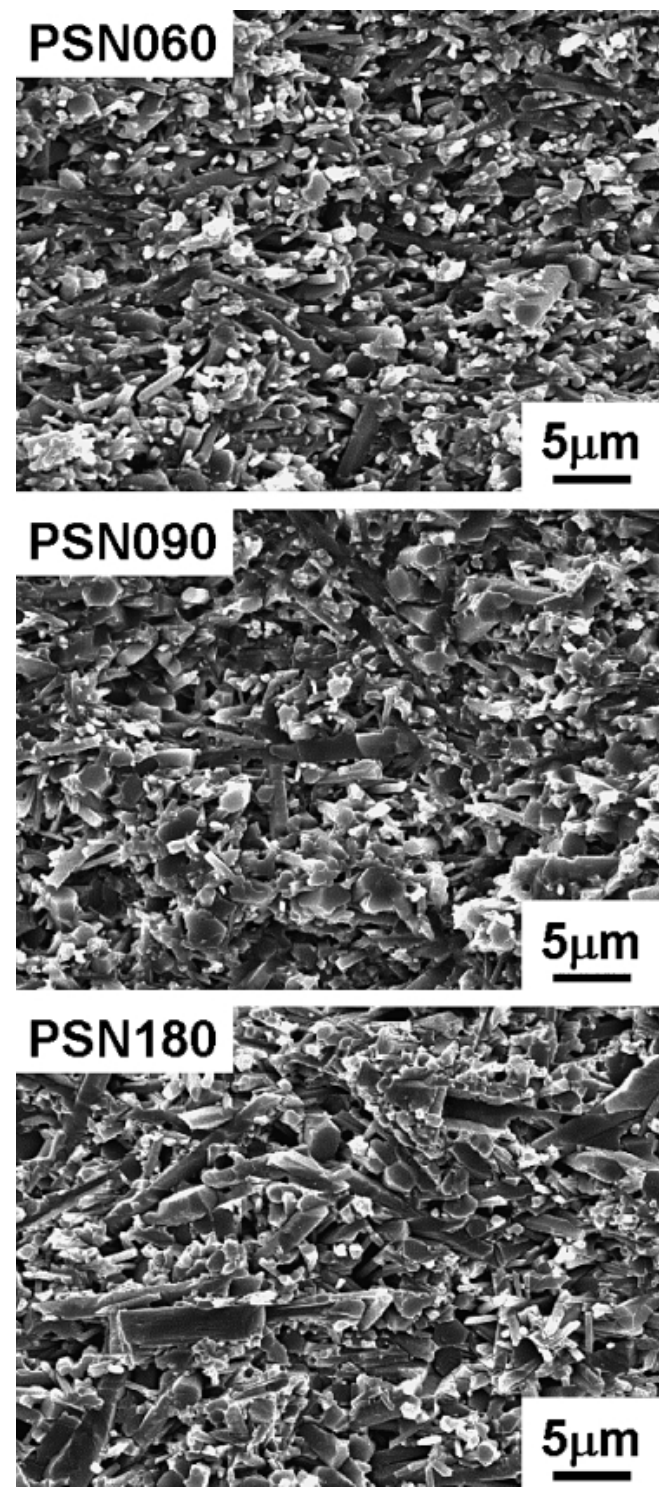

Fig. 1. Fractured surfaces of the partially sinter-forged silicon nitrides. Sinter-forging direction was vertical.

specimens exhibited strength of more than $600 \mathrm{MPa}$ at R.T. Strengths of them were almost identical despite their different microstructures (grain sizes). Strength of the previous porous anisotropic silicon nitrides with an yttria additive decreased with increased grain size. ${ }^{7)}$ Therefore, the present silicon nitrides showed a markedly different tendency from the previous ones. All specimens had much higher strength than PSN-Y at $1500^{\circ} \mathrm{C}$; for instance, PSN090 exhibited the highest strength of about $530 \mathrm{MPa}$ at $1500^{\circ} \mathrm{C}$. Strength of a commercially available silicon nitride with a lutetia additive was about $450 \mathrm{MPa}$ at $1500^{\circ} \mathrm{C}^{10)-12)}$ Consequently, these fabricated specimens have similar strength to commercial ones at $1500^{\circ} \mathrm{C}$.

Fracture energies of the specimens were high in the order of PSN180, PSN090 and PSN060 at R.T. Fracture energy of the specimens increased with increased grain size. That of PSN180 at R.T. was about $110 \mathrm{~J} \cdot \mathrm{m}^{-2}$, which was highest among the specimens. This value was lower than that of PSN-Y, ${ }^{7)}$ but two times higher than a commercial dense one of ca. $65 \mathrm{~J} \cdot \mathrm{m}^{-2} \cdot{ }^{16)}$ Fracture energies of all specimens increased monotonously against the temperature; they exceeded 


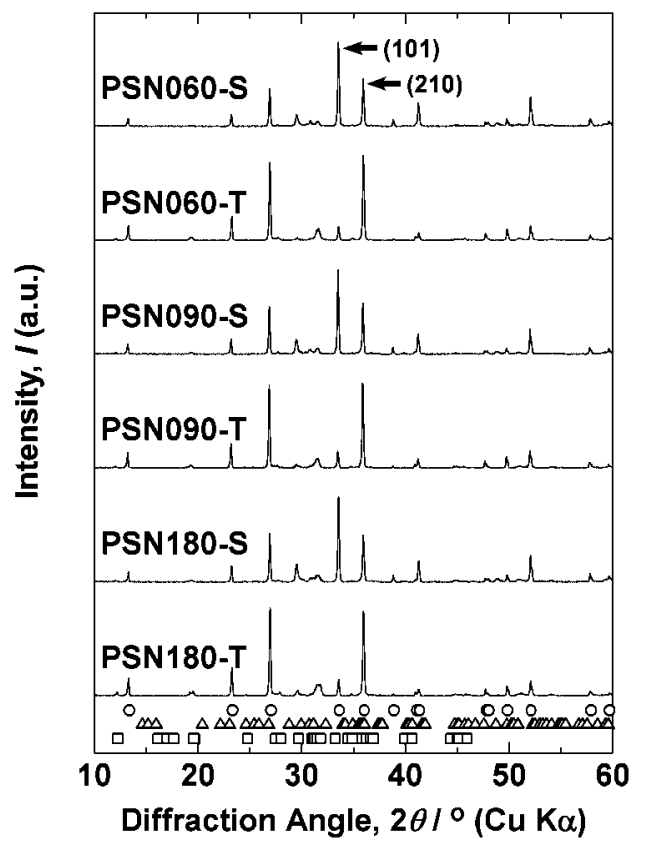

Fig. 2. Results of X-ray diffraction analysis of the fabricated specimens. $S$ and $T$ indicate the planes where observations were performed. $\bigcirc-\mathrm{Si}_{3} \mathrm{~N}_{4}, \triangle \mathrm{Lu}_{2} \mathrm{SiO}_{5}, \square \mathrm{Lu}_{4} \mathrm{Si}_{2} \mathrm{O}_{7} \mathrm{~N}_{2}$.

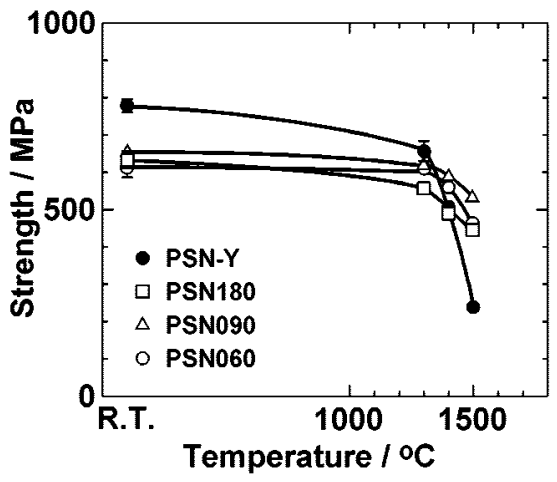

Fig. 3. Temperature dependence of strength of the partially sinterforged silicon nitrides. Results were compared to those of a previous porous anisotropic silicon nitride with an yttria additive (PSN-Y).

$150 \mathrm{~J} \cdot \mathrm{m}^{-2}$ at $1500^{\circ} \mathrm{C}$. Increasing rates were high in the order of PSN060, PSN090 and PSN180. Fracture energy of PSN-Y increased up to $1300^{\circ} \mathrm{C}$, then decreased at $1400^{\circ} \mathrm{C}$. Specimens with lutetia additive are considered to show similar behavior at higher temperatures above $1500^{\circ} \mathrm{C}$.

Superior mechanical properties in porous anisotropic silicon nitrides have been understood as the following. At R.T., concurrent achievement of strength and fracture energy is very likely the result of grain alignment effects and the presence of pores between grains. ${ }^{6), 7)}$ Alignment of rod-like grains leads to an effective operation of grain bridging and pull-out, ${ }^{17), 18)}$ which are major crack-wake toughening mechanisms in silicon nitride. ${ }^{19)}$ Fracture energy is presumably attributable to sliding resistance during this pull-out. In silicon nitride with aligned grains, fracture resistance is steeply raised in short crack propagation, namely steep $R$-curve behavior. ${ }^{17), 18)}$ This steep $R$-curve behavior also engenders improved strength. The pores around the aligned rod-like grains presumably enhance grain

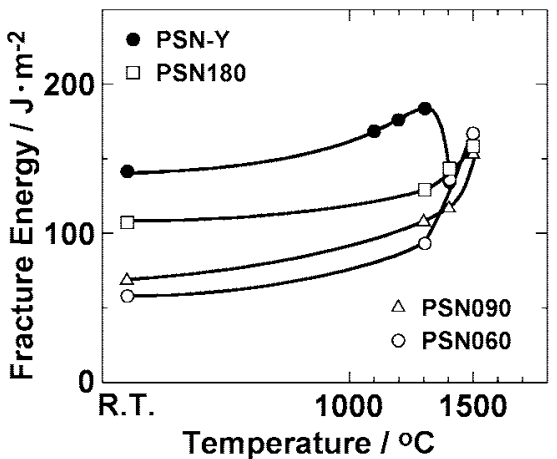

Fig. 4. Temperature dependence of fracture energy of the partially sinter-forged silicon nitrides. Results were compared to those of a previous porous anisotropic silicon nitride with an yttria additive (PSN-Y).

pull-out and bridging, leading to much higher fracture energy. ${ }^{8)}$ At elevated temperatures, mechanical properties have been considered in relation with softening of grain boundary glassy phase. ${ }^{9)}$ Strength of silicon nitride decreases as the glassy phase softens. This softened glassy phase also enhances viscoelastic behavior and pull-out of rod-like grains without being broken. In porous silicon nitride, effects of softening on pull-out seemed to be reduced because pull-out of grains had already been enhanced at R.T. Thereby, the fracture energy increment was small. Moreover, at much higher temperatures, the glassy phase was so softened that bridging and pull-out could not work effectively, resulting in the decrement of fracture energy.

Fundamentally, the fabricated porous anisotropic silicon nitrides with lutetia additive are considered to follow the behaviors explained above. However, their mechanical behaviors seemed to differ somewhat from the previous ones with yttria additive. The following interesting behaviors were observed: i) specimens exhibited almost equal strengths at R.T. despite their different grain size; ii) fracture energy was lower compared to PSN-Y; iii) strength was low at R.T., but higher at elevated temperatures in comparison to PSN-Y; iv) incremental rates of fracture energies were different at elevated temperatures; and v), decrease of fracture energy was not observed at elevated temperatures.

Strength at R.T., mentioned in i), is considered in relation with the fracture energy. PSN060 exhibited low fracture energy. This means toughening mechanism does not work effectively because of its small grain size. Some of the authors examined $R$-curve behavior in anisotropic dense silicon nitrides. ${ }^{18)}$ Steep $R$-curve behavior is shown in the silicon nitride having a lot of grains which can contribute to grain bridging. Smaller grains do not seem to contribute to the bridging. This tendency should be the same in porous anisotropic silicon nitrides. Steep $R$-curve behavior is expected to be low in the porous anisotropic silicon nitrides with smaller grains, which leads to lowered strength. This should be the reason why the specimens with smaller grains showed reduced strengths. The result that specimens with different grain size exhibited almost identical strengths seemed accidental.

Lower fracture energy, ii), is very likely the result of the property of grain boundary glassy phase containing lutetium. Fracture toughness of dense silicon nitrides with lutetia additive is strongly dependent on their compositions and sintering temperatures. ${ }^{20), 21)}$ Grain boundary structure is considered to affect the pull-out and bridging behaviors in such dense ones, 


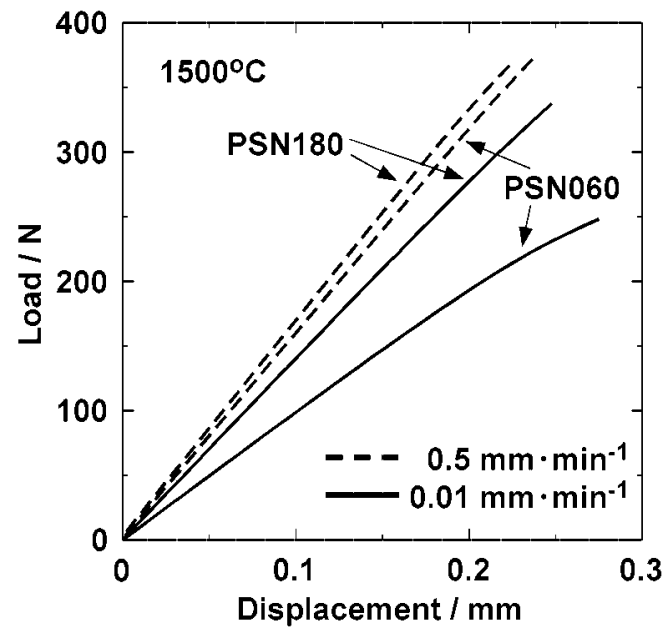

Fig. 5. Low displacement rate bending test of the partially sinterforged silicon nitrides. Testing was conducted at $1500^{\circ} \mathrm{C}$; the displacement rate was $0.01 \mathrm{~mm} \cdot \mathrm{min}^{-1}$.

however, the grain boundary condition to desire the behaviors is still unknown. In these porous silicon nitrides, the property of grain boundary glassy phase must be important as well. Detailed observation is required to discuss why the fracture energies of these specimens with lutetia additive were lower compared to the specimens with yttria additive.

High strength at elevated temperatures, iii), is also caused by the lutetia additive. In usual silicon nitrides, softening of the grain boundary glassy phase at elevated temperatures degrades strength. Becher et al. reported glass transition temperatures of $\mathrm{Si}-\mathrm{Al}-\mathrm{O}-\mathrm{N}-\mathrm{Re}(\mathrm{Re}=\mathrm{La}, \mathrm{Nd}, \mathrm{Gd}, \mathrm{Y}$, and $\mathrm{Lu})$ glasses. ${ }^{22)}$ They revealed that softening temperature of the bulk glass containing lutetium is $10^{\circ} \mathrm{C}$ higher than that with yttrium. Still, the silicon nitride with lutetia additive exhibits better strength at elevated temperatures in comparison to that with yttria additive. ${ }^{10)-12), 23)}$ Therefore, high strength at elevated temperatures in present porous silicon nitrides should be caused by the lutetia additive. Effect of lutetia additive on high temperature strength is under discussion.

Increment rates of fracture energies, iv), were different at elevated temperatures; namely, fracture energy of PSN060 increased greatly. To determine viscoelastic behavior during the CNB tests, a low displacement rate (ca. $0.01 \mathrm{~mm} \mathrm{~min}^{-1}$ ) bending test was conducted at $1500^{\circ} \mathrm{C}$. Load-displacement curves of the test are shown in Fig. 5, together with the results from normal bending test. In the low displacement rate test, PSN060 and PSN180 exhibited strengths of $295 \mathrm{MPa}$ and 405 $\mathrm{MPa}$, respectively, which were lower than the results from normal bending tests, $460 \mathrm{MPa}$ and $450 \mathrm{MPa}$. Gradient of the load-displacement curves decreased as displacement rate becomes low. The difference between the normal and low displacement rate tests was large in PSN060. Thus, PSN060 was strongly affected by softening, and viscoelastic behavior was largely enhanced in it. This is the reason why fracture energy of PSN060 increased greatly at elevated temperatures.

Decrease of fracture energies, v), was not observed up to $1500^{\circ} \mathrm{C}$. In the case of PSN-Y, decrement was considered to result from over-softening of grain boundary glassy phase. ${ }^{9)}$ Compared to PSN-Y, strength degradation at elevated temperatures was smaller in the specimens with lutetia additive. Thus, softening behavior of grain boundary glassy phase is moderate in the specimens with lutetia additive. Decrease of fracture energy should be observed at temperatures above $1500^{\circ} \mathrm{C}$, where over-softening will occur.

As discussed, some of the interesting mechanical behaviors were successfully elucidated. However, several problems, especially relating to the properties of grain boundary glassy phase containing lutetium, still remain. Investigations of such glassy phase are under progress. These investigations will be helpful to discuss the remaining problems.

\section{Conclusions}

Porous anisotropic silicon nitrides with lutetia additive were fabricated using a partial sinter-forging technique in which uniaxial pressure was applied after heating up to the sinterforging temperature. Rod-like silicon nitride grains were formed during the heating, and they were aligned by the subsequent forging. Three types of specimens with different grain size were fabricated by changing the partial sinter-forging time from 60 to $180 \mathrm{~min}$ at $1900^{\circ} \mathrm{C}$. Mechanical properties of the fabricated specimens were investigated in the temperature range from R.T. to $1500^{\circ} \mathrm{C}$. Specimen strength after sinterforging for $180 \mathrm{~min}$ was more than $600 \mathrm{MPa}$ at R.T.; that specimen had porosity of about $23 \%$ and the largest grains among the three specimens. It maintained more than $450 \mathrm{MPa}$ even at $1500^{\circ} \mathrm{C}$. Respective fracture energies at R.T. and $1500^{\circ} \mathrm{C}$ were 110 and $150 \mathrm{~J} \cdot \mathrm{m}^{-2}$.

Concurrent achievement of high strength and fracture energy is very likely the result of combined effects of grain alignment, presence of pores between grains, and particularly, lutetia sintering additive. Grain alignment and presence of pores are advantageous to achieve improved strength and fracture energy because they realize effective operation of grain bridging and enhanced pull-out. High strength at elevated temperatures is caused by the lutetia sintering additive.

Acknowledgments This work was supported by Ministry of Economy, Trade and Industry (METI), Japan under its Synergy Ceramics Project. The work was partially supported by New Energy and Industrial Technology Development Organization (NEDO). The authors are members of the Joint Research Consortium of Synergy Ceramics.

\section{References}

1) Shigegaki, Y., Brito, M. E., Hirao, K., Toriyama, M. and Kanzaki, S., J. Am. Ceram. Soc., Vol. 80, pp. 495-498 (1997).

2) Kawai, C. and Yamakawa, A., J. Am. Ceram. Soc., Vol. 80, pp. 2705-2708 (1997).

3) Yang, J. F. and Ohji, T., Ceram. Trans., Vol. 115, pp. 481-488 (2000).

4) Inagaki, Y., Ohji, T., Kanzaki, S. and Shigegaki, Y., J. Am. Ceram. Soc., Vol. 83, pp. 1807-1809 (2000).

5) Yang, J. F., Zhang, G. J. and Ohji, T., J. Mater. Res., Vol. 16, pp. 1916-1918 (2001).

6) Kondo, N., Suzuki, Y. and Ohji, T., J. Mater. Res., Vol. 16, pp. 32-34 (2001).

7) Kondo, N., Inagaki, Y., Suzuki, Y. and Ohji, T., Mater. Sci. Eng. A, Vol. 335, pp. 26-31 (2002).

8) Inagaki, Y., Kondo, N. and Ohji, T., J. Eur. Ceram. Soc., Vol. 22, pp. 2489-2494 (2002).

9) Kondo, N., Inagaki, Y., Yang, J. F. and Ohji, T., J. Ceram. Soc. Japan, Vol. 111, pp. 285-287 (2003).

10) Tanaka, K., Tsuruzono, S. and Terazono, H., Proc. of 6th International Symposium on Ceramic Materials and Components for Engines, Oct. 19-23, 1997, Arita, Japan), Ed. by Niihara, K., Hirano, S., Kanzaki, S., Komeya, K. and Morinaga, K. (1997) pp. 248-252.

11) Ohji, T., Ceram. Eng. and Sci. Proc., Vol. 22 (3), pp. 159-166 (2001).

12) Lofaj, F., Wiederhorn, S. M., Long, G. G., Hockey, B. J., 
Jemian, P. R., Browder, L., Andreason, J. and Taeffner, U., J. Eur. Ceram. Soc., Vol. 22, pp. 2479-2487 (2002).

13) Ohji, T., Goto, Y. and Tsuge, A., J. Am. Ceram. Soc., Vol. 74, pp. 739-745 (1991).

14) Hirosaki, N., Yamamoto, Y., Nishimura, T. and Mitomo M., J. Am. Ceram. Soc., Vol. 85, pp. 2861-2863 (2002).

15) Yoon, S. Y., Akatsu, T. and Yasuda, E., J. Mater. Sci., Vol. 32, pp. 3813-3819 (1997).

16) Kondo, N., in preparation.

17) Ohji, T., Hirao, K. and Kanzaki, S., J. Am. Ceram. Soc., Vol.78, pp. 3125-3128 (1995).

18) Ohji, T., Kondo, N., Suzuki, Y. and Hirao, K., Mater. Lett.,
Vol. 40, pp. 5-10 (1999)

19) Becher, P. F., J. Am. Ceram. Soc., Vol. 74, pp. 255-269 (1991).

20) Kondo, N., Ishizaki, M. and Ohji, T., Proc. Fourth International Symposium on Nitrides, Oct. 20-22 (2003) Mons, Belgium, in press.

21) Kondo, N., Ishizaki, M. and Ohji, T., Ceram. Eng. and Sci. Proc., Vol. 25 (2004) in press.

22) Becher, P. F., Waters, S. B., Westmoreland, C. G. and Riester, L., J. Am. Ceram. Soc., Vol. 85, pp. 897-902 (2002).

23) Rendtel, A., Huebner, H., Herrmann, M. and Schubert, C., J. Am. Ceram. Soc., Vol. 81, pp. 1109-1120 (1998). 